Article

\title{
Assessing the Single and Combined Toxicity of Chlorantraniliprole and Bacillus thuringiensis (GO33A) against Four Selected Strains of Plutella xylostella (Lepidoptera: Plutellidae), and a Gene Expression Analysis
}

\author{
Muhammad Zeeshan Shabbir ${ }^{1,2}$, Ling He ${ }^{1,2}$, Changlong Shu ${ }^{3}$, Fei Yin ${ }^{1,2}$, Jie Zhang ${ }^{3}$ and Zhen-Yu Li ${ }^{1,2, *}$ \\ 1 Institute of Plant Protection, Guangdong Academy of Agricultural Sciences, Guangzhou 510640, China; \\ zeeshan@gdppri.com (M.Z.S.); linghe02@hotmail.com (L.H.); yinfei@gdaas.cn (F.Y.) \\ 2 Guangdong Provincial Key Laboratory of High Technology for Plant Protection, Guangzhou 510640, China \\ 3 State Key Laboratory for Biology of Plant Diseases and Insect Pests, Institute of Plant Protection, Chinese \\ Academy of Agricultural Sciences, Beijing 100094, China; clshu@ippcaas.cn (C.S.); jiezhang@caas.net.cn (J.Z.) \\ * Correspondence: lizhenyu@gdaas.cn
}

Citation: Shabbir, M.Z.; He, L.; Shu, C.; Yin, F.; Zhang, J.; Li, Z.-Y.

Assessing the Single and Combined Toxicity of Chlorantraniliprole and Bacillus thuringiensis (GO33A) against Four Selected Strains of Plutella xylostella (Lepidoptera: Plutellidae), and a Gene Expression Analysis. Toxins 2021, 13, 227. https:// doi.org/10.3390/toxins 13030227

Received: 24 February 2021

Accepted: 18 March 2021

Published: 22 March 2021

Publisher's Note: MDPI stays neutral with regard to jurisdictional claims in published maps and institutional affiliations.

Copyright: (c) 2021 by the authors. Licensee MDPI, Basel, Switzerland. This article is an open access article distributed under the terms and conditions of the Creative Commons Attribution (CC BY) license (https:// creativecommons.org/licenses/by/ $4.0 /)$.

\begin{abstract}
Concerns about resistance development to conventional insecticides in diamondback moth (DBM) Plutella xylostella (L.), the most destructive pest of Brassica vegetables, have stimulated interest in alternative pest management strategies. The toxicity of Bacillus thuringiensis subsp. aizawai (Bt GO33A) combined with chlorantraniliprole (Chl) has not been documented. Here, we examined single and combined toxicity of chlorantraniliprole and Bt to assess the levels of resistance in four DBM strains. Additionally, enzyme activities were tested in field-original highly resistant (FOH-DBM), Bt-resistant (Bt-DBM), chlorantraniliprole-resistant (CL-DBM), and Bt + chlorantraniliprole-resistant (BtC-DBM) strains. The Bt product had the highest toxicity to all four DBM strains followed by the mixture of insecticides $(\mathrm{Bt}+\mathrm{Chl})$ and chlorantraniliprole. Synergism between $\mathrm{Bt}$ and chlorantraniliprole was observed; the combination of $\mathrm{Bt}+(\mathrm{Bt}+\mathrm{Chl})\left(1: 1, \mathrm{LC}_{50}: \mathrm{LC}_{50}\right)$ was the most toxic, showing a synergistic effect against all four DBM strains with a poison ratio of 1.35, 1.29, 1.27, and 1.25. Glutathione S-transferase (GST) and carboxyl-esterase (CarE) activities showed positive correlations with chlorantraniliprole resistance, but no correlation was observed with resistance to $\mathrm{Bt}$ and $\mathrm{Bt}+\mathrm{Chl}$ insecticides. Expression of genes coding for PxGST, CarE, AChE, and MFO using qRT-PCR showed that the PxGST and MFO were significantly overexpressed in Bt-DBM. However, AChE and CarE showed no difference in the four DBM strains. Mixtures of Bt with chlorantraniliprole exhibited synergistic effects and may aid the design of new combinations of pesticides to delay resistance in DBM strains substantially.
\end{abstract}

Keywords: Bacillus thuringiensis; biochemical assay; chlorantraniliprole; joint action toxicity; resistant management

Key Contribution: In the current work, four diamondback moth strains were reared in a greenhouse for several generations from where we examined resistance to $\mathrm{Bt}$ (GO33A) and chlorantraniliprole singly and in combination. The combination of Bt with chlorantraniliprole exhibited synergistic effects and is helpful for designing new combinations of insecticides that will substantially delay resistance in the diamondback moth.

\section{Introduction}

The diamondback moth (DBM), Plutella xylostella (L.) (Lepidoptera: Plutellidae), is a major pest of Brassica vegetables, reported in more than 80 countries, and causes severe damage to vegetable crops in China and wherever it occurs [1-6]. The annual yield losses and cost associated with the management of diamondback moth are estimated to be billions of dollars worldwide [5]. Insecticides remain the primary approach for management of 
P. xylostella. The most commonly used insecticides for cruciferous vegetables in China are diamides, pyrethrins, avermectins, and Bacillus thuringiensis (Bt) [7]. Furthermore, the evolution of resistance to a wide range of insecticides, and subsequent spray failures, have been reported for P. xylostella, including Bt products [1,4,8,9].

The understanding of the resistance mechanism in target pests to insecticides is essential for an effective control strategy. Mechanism of resistance can involve higher levels of detoxifying enzymes or metabolic resistance, reduced penetration and changes in the target sites due to mutations [10-12]. The common mechanisms of metabolic resistance to insecticides include enhanced carboxyl-esterase (CarE), glutathione S-transferases (GST), and cytochrome P450 monooxygenase (MFO) activity [13-15]. The insensitivity of the target site to organophosphates and pyrethroids is related to the activity of acetylcholinesterase (AChE) [16]. The correlations between detoxifying enzymes and insecticide resistance have been reported extensively [4], including the overexpression of enzymatic detoxification involved in resistance in P. xylostella [9].

Transgenic crops expressing various Bt toxins have been extensively adopted to combat lepidopteran pests [17-19]. However, the widespread usage of a single transgenic product raises the prospect of insect resistance to Bt proteins, thus reducing the efficacy of Bt crops. Several lepidopteran pests have developed resistance to various $\mathrm{Bt}$ toxins, including Cry1Ac, Cry1Ie, Cry1F, and Cry1Ah, both in the field and in laboratory experiments [19-22]. To overcome this issue, $\mathrm{Bt}$ toxins are often used in combinations with other insecticides so as to delay resistance evolution in lepidopteran pests [23,24].

In the last decade, considerable progress has been made in the assessment of toxicity of combinations of toxins or mixtures against several lepidopteran pests. It is common to perceive that increased toxicity comes from exposure to compounds in a mixture or combination rather than to a single product. Chemical combinations can demonstrate additive, synergistic and antagonistic effects even if used in low concentrations [25]. Mixtures of numerous pesticides are being used against pests to help ensure crop production [26-28]. The strategy of using a mixture of chemicals has been studied extensively $[23,29,30]$. However, research on testing combinations of Bt toxins and insecticides is limited. Thus, determining how a mixture of Bt and pesticides affect DBM populations will throw much-needed light on how to improve the management of this major pest.

Successful development of resistance management strategies needs careful selection of the insecticide type to apply. Here, we assess whether a Bt product and chlorantraniliprole (Chl) will delay resistance evolution in strains of P. xylostella. Bt and chlorantraniliprole were chosen because no one has reported on their effects as a mixture/combination, and we do so using four strains of DBM. Here, we determined the detoxifying enzyme activity of glutathione S-transferase (GST), cytochrome P450 monooxygenase (MFO), acetylcholinesterase (AChE), and carboxyl-esterase (CarE) to find a correlation between the Bt product and chlorantraniliprole. In addition, we compared the gene expression among the DBM strains, using qRT-PCR. This study provides important information for developing successful resistance management strategies for DBM. It will help delay resistance evolution through the application of tactics such as Bt and chlorantraniliprole mixtures and rotation of insecticides with different modes of action.

\section{Results}

\subsection{The Resistance Level of Greenhouse Strains of P. xylostella to Three Insecticides}

Leaf-dip bioassays revealed that the different insecticides varied in their toxicities to the four DBM strains (Table 1). The chlorantraniliprole (CL)-DBM strain developed a moderate level of resistance (31.2-fold) to chlorantraniliprole compared with larvae from the field-original highly resistant (FOH)-DBM. Similarly, the Bt-DBM and Bt + chlorantraniliprole (BtC)-DBM strains showed a moderate level of resistance to chlorantraniliprole, with a resistance ratio of 24.2- and 27.3-fold, respectively (Table 1).

The Bt product (GO33A) displayed high toxicity to all four strains of DBM. The $\mathrm{LC}_{50}$ value of Bt-DBM was $16.29 \mathrm{mg} \mathrm{L}^{-1}$, showing an 18.7-fold resistance level compared to FOH- 
DBM. However, the BtC-DBM and CL-DBM showed little difference in their resistance to the Bt toxin. These data indicated that no cross-resistance was observed in these strains concerning Bt product (Table 1).

Table 1. Toxicity of Bacillus thuringiensis (Bt) and chlorantraniliprole against four strains of Plutella xylostella.

\begin{tabular}{|c|c|c|c|c|c|c|}
\hline Insecticide & Strains & Slope \pm SE & $\mathrm{LC}_{50}(95 \% \mathrm{FL})(\mathrm{mg} / \mathrm{L})$ & df & $x^{2}$ & $\mathbf{R R}^{\mathrm{a}}$ \\
\hline \multirow[t]{4}{*}{ Chlorantraniliprole } & $\mathrm{FOH}-\mathrm{DBM}{ }^{\mathrm{c}}$ & $1.075 \pm 0.277$ & $7.76(1.277-16.26)$ & 5 & 0.744 & - \\
\hline & Bt-DBM ${ }^{\mathrm{d}}$ & $1.057 \pm 0.209$ & $188.08(112.04-423.76)$ & 5 & 1.642 & 24.2 \\
\hline & CL-DBM $^{\mathrm{e}}$ & $0.902 \pm 0.205$ & $271.87(143.82-927.94)$ & 5 & 1.069 & 31.2 \\
\hline & BtC-DBM $^{f}$ & $0.791 \pm 0.215$ & 211.52 (104.06-901.522) & 5 & 0.731 & 27.3 \\
\hline \multirow[t]{4}{*}{$\mathrm{Bt}$} & FOH-DBM & $1.119 \pm 0.175$ & $0.87(0.521-1.308)$ & 5 & 0.686 & - \\
\hline & Bt-DBM & $0.863 \pm 0.166$ & $16.29(9.36-42.19)$ & 5 & 0.627 & 18.7 \\
\hline & CL-DBM & $1.726 \pm 0.117$ & $1.58(1.13-2.18)$ & 5 & 4.577 & 1.8 \\
\hline & BtC-DBM & $1.592 \pm 0.195$ & $1.13(0.7-1.69)$ & 5 & 5.097 & 1.3 \\
\hline \multirow[t]{4}{*}{$\mathrm{Bt}+\mathrm{Chl}^{\mathrm{b}}$} & FOH-DBM & $1.061 \pm 0.253$ & $5.71(1.388-11.05)$ & 5 & 2.251 & - \\
\hline & Bt-DBM & $1.111 \pm 0.219$ & $36.99(21.51-62.92)$ & 5 & 0.694 & 6.5 \\
\hline & CL-DBM & $1.022 \pm 0.262$ & $27.01(16.39-42.98)$ & 5 & 1.403 & 4.7 \\
\hline & BtC-DBM & $1.134 \pm 0.187$ & $30.25(18.96-47.21)$ & 5 & 0.811 & 5.3 \\
\hline
\end{tabular}

a $\mathrm{RR}$, resistance ratio $=\mathrm{LC}_{50}$ of a particular strain divided by $\mathrm{LC}_{50}$ of the field-original strain. ${ }^{\mathrm{b}} \mathrm{Bt}+\mathrm{Chl}$, the insecticide mixture of $\mathrm{Bt}(\mathrm{G} 033 \mathrm{~A})$ and chlorantraniliprole (1:1). ${ }^{\mathrm{C}} \mathrm{FOH}-\mathrm{DBM}$, the field-original highly resistant strain. ${ }^{\mathrm{d}}$ Bt-DBM, the resistant strain treated with Bt toxin (G033A). ${ }^{\text {e }}$ CL-DBM, the resistant strain treated with chlorantraniliprole insecticide. ${ }^{\mathrm{f}} \mathrm{BtC}-\mathrm{DBM}$, the resistant strain of DMB selected with a mixture of $\mathrm{Bt}$ and chlorantraniliprole.

The $\mathrm{LC}_{50}$ of the binary mixtures of the Bt product and chlorantraniliprole $(\mathrm{Bt}+\mathrm{Chl})$ were determined to understand the interaction effect of these chemicals towards four strains of DBM. The strain selected with the Bt product (Bt-DBM) had a 6.5-fold resistance to the $\mathrm{Bt}+\mathrm{Chl}$ mixture, and selection with chlorantraniliprole (CL-DBM) and BtC-DBM caused the same level of resistance to the binary mixture $(\mathrm{Bt}+\mathrm{Chl})$ (Table 1). No significant difference was observed in the $\mathrm{LC}_{50}$ values of the CL-DBM and BtC-DBM strains. Based on these results, the toxicity of the three tested insecticides to four greenhouse DBM strains was ranked as $\mathrm{Bt}>\mathrm{Bt}+\mathrm{Chl}>$ chlorantraniliprole.

\subsection{Joint Action of Combinations}

The combinations of the chemicals Bt and chlorantraniliprole against the four DBM strains showed synergistic, additive, and antagonistic interactions (Table 2). The combination of $\mathrm{Bt}+(\mathrm{Bt}+\mathrm{Chl})$ exhibited the most synergistic effect with a poison ratio of 1.35 and was a major contributor to toxicity in the four DBM strains. However, the Bt $+\mathrm{Chl}(1: 1)$ mixture exhibited an additive effect within the strains, except for FOH-DBM, and showed significantly lower toxicity. The toxicities of the treatments differed among the four DBM strains (Table 2).

Table 2. Joint action of Bt and chlorantraniliprole against Plutella xylostella strains.

\begin{tabular}{ccccc}
\hline Strains & Treatment $^{\mathrm{a}}$ & Actual Mortality (\%) $^{\mathrm{b}}$ & Theoretical Mortality (\%) $^{\mathrm{c}}$ & Poison Ratio $^{\mathrm{d}}$ \\
\hline FOH-DBM & $\mathrm{Bt}+\mathrm{Chl}$ & $50.00 \pm 5.77$ & 51.67 & $0.96 \pm 0.11^{\mathrm{b}}$ \\
& $\mathrm{Bt}+(\mathrm{Bt}+\mathrm{Chl})$ & $73.33 \pm 3.33$ & 53.33 & $1.35 \pm 0.06^{\mathrm{a}}$ \\
& $\mathrm{Chl}+(\mathrm{Bt}+\mathrm{Chl})$ & $60.00 \pm 3.33$ & 48.33 & $1.24 \pm 0.02^{\mathrm{a}, \mathrm{b}}$ \\
$\mathrm{Bt}-\mathrm{bBM}$ & $\mathrm{Bt}+\mathrm{Chl}$ & $56.67 \pm 3.33$ & 56.67 & $1.00 \pm 0.05^{\mathrm{b}}$ \\
& $\mathrm{Bt}+(\mathrm{Bt}+\mathrm{Chl})$ & $76.67 \pm 3.33$ & 60.00 & $1.27 \pm 0.10^{\mathrm{a}}$ \\
& $\mathrm{Chl}+(\mathrm{Bt}+\mathrm{Chl})$ & $66.67 \pm 3.33$ & 53.33 & $1.24 \pm 0.06^{\mathrm{a}, \mathrm{b}}$ \\
CL-DBM & $\mathrm{Bt}+\mathrm{Cl}$ & $53.33 \pm 3.33$ & 53.33 & $1.00 \pm 0.06^{\mathrm{b}}$ \\
& $\mathrm{Bt}+(\mathrm{Bt}+\mathrm{Chl})$ & $63.33 \pm 3.33$ & 50.00 & $1.29 \pm 0.10^{\mathrm{a}}$ \\
BtC-DBM & $\mathrm{Chl}+(\mathrm{Bt}+\mathrm{Chl})$ & $56.67 \pm 3.33$ & 56.67 & $1.27 \pm 0.06^{\mathrm{a}, \mathrm{b}}$ \\
& $\mathrm{Bt}+\mathrm{Chl}$ & $73.33 \pm 3.33$ & 58.33 & $1.00 \pm 0.06^{\mathrm{b}}$ \\
& $\mathrm{Bt}+(\mathrm{Bt}+\mathrm{Chl})$ & $66.67 \pm 3.33$ & 55.00 & $1.25 \pm 0.05^{\mathrm{a}}$ \\
& $\mathrm{Chl}+(\mathrm{Bt}+\mathrm{Chl})$ & & $1.21 \pm 0.06^{\mathrm{a}, \mathrm{b}}$ \\
\hline
\end{tabular}

${ }^{a}$ Combination of $\mathrm{Bt}(\mathrm{G} 033 \mathrm{~A})$ and $\mathrm{Chl}$ (chlorantraniliprole) $\left(1: 1, \mathrm{LC}_{50}: \mathrm{LC}_{50}\right){ }^{\mathrm{b}}$ Actual mortality data are the mean of three replicates represented as the mean \pm standard error $(n=3)$. ${ }^{c}$ Mean values of the mortality of each insecticide in the mixture. ${ }^{\mathrm{d}}$ Poison ratio $>1.0$ defined as a synergistic effect, 1.0 as an additive effect, and $<1.0$ as an antagonistic effect. A significant difference was observed between the treatments $(\mathrm{df}=2,8 ; \mathrm{FOH}-\mathrm{DBM}$ : F $=7.89$, $p=0.0209$; Bt-DBM: $\mathrm{F}=6.72, p=0.0294 ; \mathrm{CL}-\mathrm{DBM}: \mathrm{F}=6.70, p=0.0295$; BtC-DBM: $\mathrm{F}=5.44, p=0.0449)$. Data are the mean of three replications and represented as the mean \pm standard error. Means in the same column followed by the same letter are not significantly different (GLM, LSD, $p<0.05)$. 


\subsection{Detoxifying Enzyme Activities}

The CL-DBM strain showed a significant increase in PxGST activity using CDNB as substrate, whereas the Bt-DBM and BtC-DBM strains revealed decreased PxGST activities compared to the FOH-DBM (Figure 1A). The increasing activity of PxGST might be contributing to resistance to chlorantraniliprole insecticide in the CL-DBM strain.

The acetyl cholinesterase (AChE) activity of the third instar larvae of the DBM strains indicated that only the Bt product significantly inhibits the AChE activity. Chlorantraniliprole and the mixture of $\mathrm{Bt}$ and chlorantraniliprole $(\mathrm{Bt}+\mathrm{Chl})$ showed an increased $\mathrm{AChE}$ activity but was not statistically significant compared to the FOH-DBM (Figure 1B).

The results of the carboxyl-esterase (CarE) activity indicated that CL-DBM showed significantly increased activity compared to the FOH-DBM, whereas the Bt-DBM and BtC-DBM strains showed considerably decreased CarE activity (Figure 1C).

The cytochrome P450 monooxygenases (MFO) activity was significantly enhanced in the FOH-DBM strain. However, the strains selected with Bt and chlorantraniliprole showed lower MFO activities (Figure 1D).
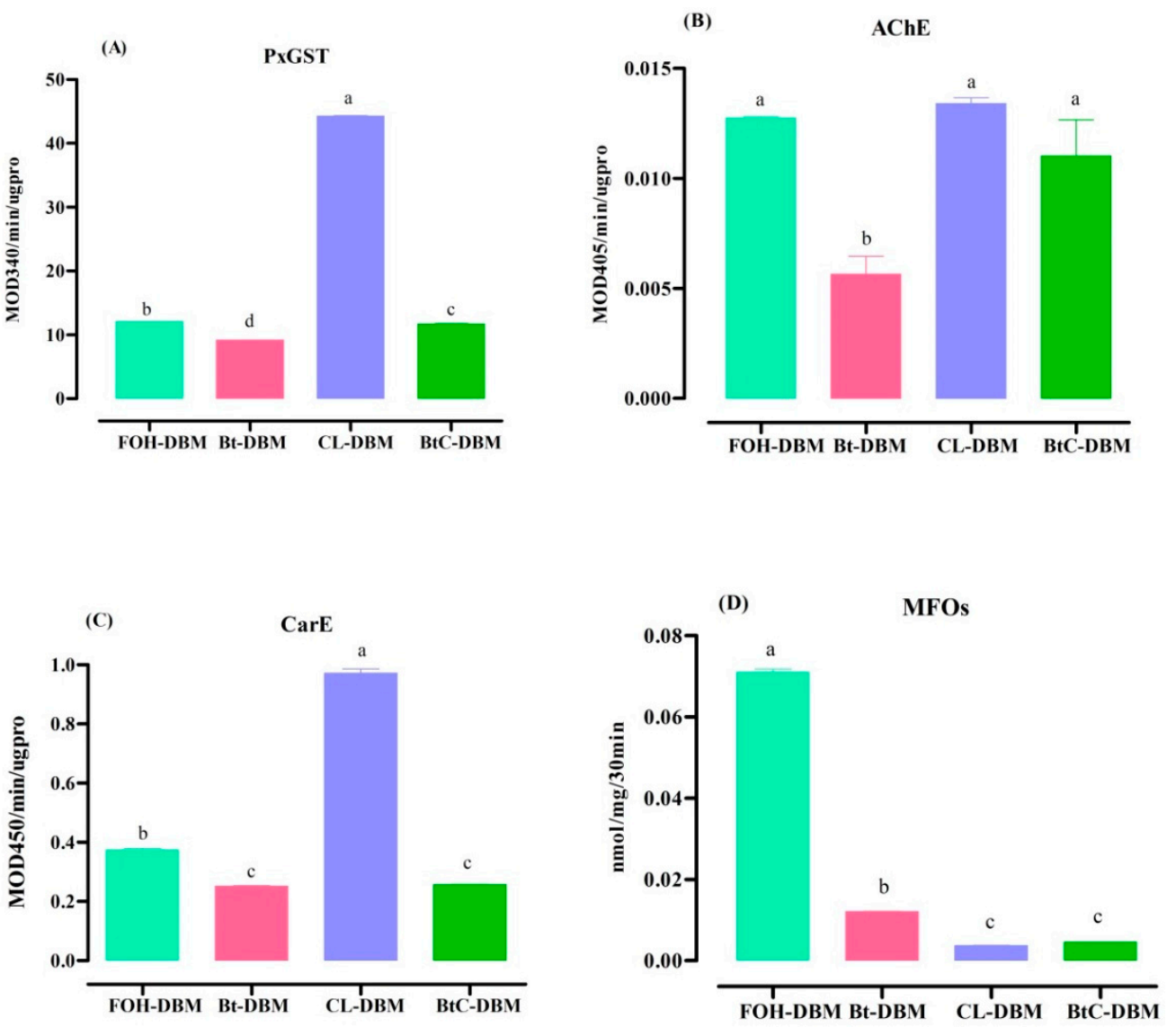

\section{Strains}

Figure 1. Activities of detoxifying enzymes in different strains of Plutella xylostella: (A) glutathione S-transferase (PxGST) activity; (B) acetylcholine esterase (AChE) activity; (C) carboxyl esterase (CarE) activity; (D) cytochrome P450 monooxygenase (MFO) activity. A significant difference was observed between the strains ( $\mathrm{df}=3$, 11; PxGST: $\mathrm{F}=105624.61, p<0.001$; AChE: $\mathrm{F}=14.37, p=0.001$; CarE: $\mathrm{F}$ $=2048.39, p<0.001$; MFO: $\mathrm{F}=7292.5, p<0.001$ ). The bars labeled with the same letter indicate no significant difference while different letters are significantly different. Data represent the mean $\pm \mathrm{SE}$ of three replications (GLM, LSD, $p<0.05)$.

\subsection{Expression Profiles of the Detoxification Genes}

The expression levels of the four selected genes (PxGST, AChE, CarE, and MFO) in the four DBM strains differed. The expression level of PxGST was significantly higher 
in Bt-DBM (8.9-fold) followed by CL-DBM (3.5-fold) and BtC-DBM (2.6-fold) (Figure 2). Similarly, the gene expression of MFO was also significantly higher in Bt-DBM (2.62-fold) compared to the other strains. The expression of AChE and CarE was higher in the resistant strains compared to FOH-DBM but were not statistically significant (Figure 2).

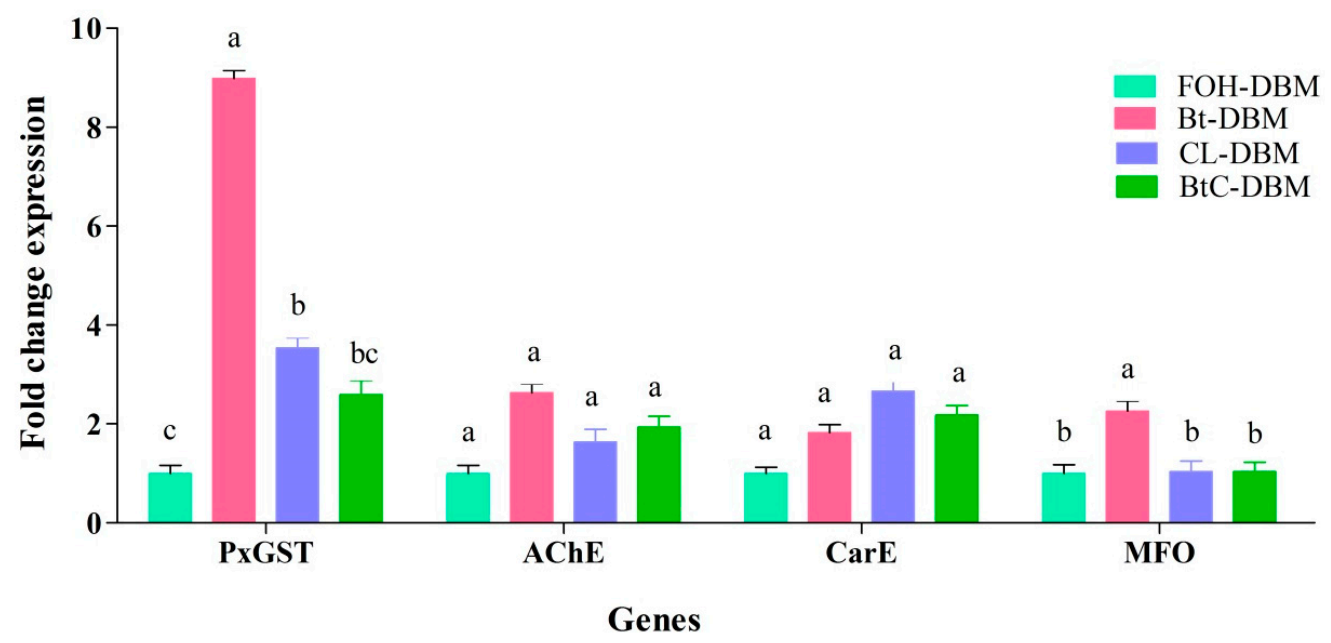

Figure 2. Differences in the fold-change expression level of the selected genes in four strains of Plutella xylostella. The gene expression data were generated by qRT-PCR analysis of four DBM strains. PxGST, glutathione S-transferase; AChE, acetylcholine esterase; CarE, carboxyl esterase; MFO, cytochrome P450 monooxygenases. The expression of the genes (PxGST and MFO) was significantly different between the strains ( $\mathrm{df}=3$, 11; PxGST: $\mathrm{F}=22.20, p=<0.001$; MFO: $\mathrm{F}=9.49, p=0.005$ ). The bars labeled with the same letter are not significantly different and with different letter are significantly different (GLM, LSD, $p<0.05)$.

\section{Discussion}

Chemical control is widely used for the management of lepidopteran pests, especially P. xylostella. However, insecticide resistance can significantly reduce the effectiveness of this strategy [31,32]. Pest resistance to pesticides fluctuates in members of the same populations due to the hereditary characteristics of strains [33], as well as many other factors [34]. Thus, the resistance evaluation of $P$. xylostella to commonly used pesticides is mainly related to developmental history, pesticide application frequency, and the actual selection pressure of each pesticide. Our study provides information that can help to extend the durability of Bt product to overcome resistance evolution based on an evaluation of four strains: three selected with Bt, chlorantraniliprole, and a mixture of Bt and chlorantraniliprole, and a control P. xylostella strain.

Among the insecticides tested, the Bt product was the most toxic against all four DBM strains, followed by the binary mixture of Bt and chlorantraniliprole (Bt + Chl) (Table 1). Chlorantraniliprole has shown less resistance when applied separately against the four DBM strains. The results show that BtC-DBM and Bt-DBM have the greatest $\mathrm{LC}_{50}$ values (188 and $211 \mathrm{mg} \mathrm{L}^{-1}$ ), resulting in a moderate cross-resistance to chlorantraniliprole with a resistance ratio of 24.2- and 27.3-fold, respectively. The resistance levels in these strains to chlorantraniliprole are not unexpected as $P$. xylostella can rapidly develop resistance to a wide range of insecticides [1]. However, the CL-DBM strain showed a 31.2-fold resistance compared to the FOH-DBM strain with respect to chlorantraniliprole. Clearly, the DBM strains exhibited different resistance levels to the tested chemicals. This variability in insecticide resistance of DBM has been explained by the difference in population and geographical distribution, as reported previously in numerous studies $[7,35,36]$. However, in our case, the strains originated from one location and were subjected to just two rounds of selection. Even with this limited selection, the toxicity of the three tested insecticides to the four DBM strains is ranked as $\mathrm{Bt}>\mathrm{Bt}+\mathrm{Chl}>$ chlorantraniliprole. A binary mixture of Bt and chlorantraniliprole did not show more toxicity to the four DBM strains compared 
to the Bt product when applied alone. These results are consistent with a previous study finding that the pyramids of the two toxins did not consistently delay resistance evolution relative to a single product in a lepidopteran pest [30].

The results of the joint action of insecticides indicated that the Bt product was more toxic to all four strains of DBM when mixed with the binary mixture Bt $+\mathrm{Chl}$. In contrast, chlorantraniliprole showed low toxicity when mixed with the binary mixture $\mathrm{Bt}+\mathrm{Chl}$ (Table 2). Our results suggest synergistic, additive, and antagonistic effects among the combinations of insecticides used against four strains of DBM. In particular, the mixture of $\mathrm{Bt}+(\mathrm{Bt}+\mathrm{Chl})\left(1: 1: 1 ; \mathrm{LC}_{50}: \mathrm{LC}_{50}\right)$ produced a synergistic activity compared to other combinations in the field-original highly resistant strain. At the $50 \%$ effect level, synergism was confirmed for these mixtures in all four DBM strains. These results are consistent with a previous study, which indicated that B. thuringiensis and the insecticides binapacryl, chlordimeform, fentin hydroxide, and tricyclohexyltin hydroxide, in combination, were synergistic and controlled P. xylostella strains [37]. Similarly, these findings confirm a previous study that verified synergistic effects for a mixture of sulfonamides applied on D. manga [38], and reports have confirmed that mixtures of chemicals have higher toxicity to target pests $[28,39]$. However, the toxic effect of a binary combination of $\mathrm{Bt}+\mathrm{Chl}$ $\left(1: 1 ; \mathrm{LC}_{50}: \mathrm{LC}_{50}\right)$ generated antagonistic effects with a poison ratio of 0.96 in FOH-DBM, but additive effects in all three selected strains of DBM. Combinations of insecticides play a meaningful role compared to single insecticide because they have multiple modes of action. Hence, chemical mixtures may be effective in management of lepidopteran pests; however, it is not clear how the synergism can be used positively. Moreover, a comprehensive understanding of the potential synergistic effects of the insecticides to non-target organisms must account for Bt and chlorantraniliprole combined.

The biochemical mechanisms of resistance have been used for studying toxin-invertebrate interactions directly in resistant and susceptible strains. It is speculated that detoxification enzymes, such as cytochrome P450 monooxygenases, glutathione S-transferase, acetyl-cholinesterase, and carboxyl-esterase, play an essential role in the metabolism of carbamates, pyrethroids, and novel insecticides in numerous insects, including $P$. $x y$ lostella $[40,41]$. We found biochemical resistance characteristics of Bt, chlorantraniliprole, and binary mixture of these chemicals against four DBM strains. Our enzyme assays showed that there was a high level of GST activity in CL-DBM compared to the other three strains. However, we found no association between GST activity and resistance to the Bt product and a mixture of $\mathrm{Bt}$ and chlorantraniliprole. This significant correlation between GST activity and chlorantraniliprole suggests that the GST gene probably confers resistance to this insecticide in P. xylostella. These findings are consistent with previous studies that the GST enzymes contribute to the detoxification of exogenous combinations of pesticides, such as indoxacarb, acephate, and chlorantraniliprole, in P. xylostella [42,43]. Furthermore, a positive correlation with GST activity was found in response to spinosad insecticide treatments [44-46]. The higher expression level of GST presumably raises the insecticide metabolism rates. Similarly, we found an association between the carboxyl-esterase (CarE) activity and resistance to chlorantraniliprole, in agreement with a previous study [34] that showed a correlation between CarE activity with abamectin resistance in P. xylostella. Previously, AChE and MFO have been found to be responsible for resistance to pyrethroids and other insecticides in P. xylostella [34,47]. However, we found no obvious correlation between $\mathrm{MFO}$ and $\mathrm{AChE}$ activities and resistance to Bt product and chlorantraniliprole.

Analysis of gene expression in four strains of DBM showed that PxGST displayed a significantly higher expression in the Bt-DBM strain than the other strains and the CarE gene expression was slightly reduced in the Bt product compared to chlorantraniliprole and the $\mathrm{Bt}+\mathrm{Chl}$ mixture. Similarly, $\mathrm{AChE}$, and MFO expression showed a moderate increase in the Bt-DBM strain compared to other resistant and FOH-DBM strains. Previously, a 1.29-fold higher ProPO activity level has been reported in a resistant P. xylostella strain compared to a susceptible strain [48]. The P450 and GST genes also have been identified to be involved in the detoxification of xenobiotics and conferring resistance [49,50]. In earlier 
work, it was reported that upregulation of genes played a significant role in the $\mathrm{Bt}$ toxin Cry1Ah resistance of O. furnacalis [51]. The higher expression of PxGST and other genes in the resistant strains as compared to the FOH-DBM strain suggested that these genes could have a significant role in Bt and chlorantraniliprole resistance of DBM. Moreover, resistance might be associated with the expression of multiple receptors between resistant and susceptible strains. Specifically, the higher expression of AChE to some extent in Bt-DBM could be due to specific binding/interference with neurotransmitters by a specific cry protein or combination of proteins. Follow-up work will be conducted to identify the specific genes linked to Bt resistance in DBM strains.

\section{Conclusions}

Bacillus thuringiensis subsp. aizawai (GO33A) had a considerable toxicity level, unlike the chlorantraniliprole insecticide and their mixture effect. The significant synergistic effects detected from binary mixtures of $\mathrm{Bt}+(\mathrm{Bt}+\mathrm{Chl})$ and $\mathrm{Chl}+(\mathrm{Bt}+\mathrm{Chl})\left(1: 1 ; \mathrm{LC}_{50}: \mathrm{LC}_{50}\right)$ in all four different strains of P. xylostella suggests a practical approach that can delay or overcome common pesticide resistance mechanisms. It is remarkable that the mixture of these chemicals retained a high level of activity against four strains of DBM, where single product did not. A strong positive correlation between the enzyme activity, especially GST and chlorantraniliprole, shows the main detoxification mechanism of resistance. However, a correlation between enzyme activities and the Bt product was not substantially identified. These results support the idea of the potential use of the Bt product in ways that will considerably delay resistance in P. xylostella. Based on the evidence presented here, we conclude that the development of resistance in different strains of P. xylostella to chlorantraniliprole may be different depending on the concentrations of the applied pesticide. Furthermore, resistant strains, having developed metabolic resistance to certain tested pesticides, might have altered sensitivity to other pesticides with different modes of action. Finally, we cannot determine how mixtures of the toxin and insecticides will be applied in the future. However, these synergistic combinations may represent a first step towards the utilization of Bt products and insecticides that will considerably delay resistance in P. xylostella.

\section{Materials and Methods}

\subsection{Selection of DBM Strains}

The four strains in the present study were Bt-resistant (Bt-DBM), chlorantraniliproleresistant (CL-DBM), Bt + chlorantraniliprole-resistant (BtC-DBM), and a field-original highly resistant (FOH-DBM) control. The latter was originally collected from the Shijing area, Guangzhou. Detailed information regarding FOH-DBM is provided in Table S1. This population was established in a greenhouse and reared on cabbage exposed to chlorantraniliprole insecticide, Bt product (GO33A), and their resistance level checked. The greenhouse was divided into four sections; in Section 1 no treatment was undertaken on plants infested with larvae; in Section 2, the cabbage plants were sprayed with Bt 4000X, $1.5 \mathrm{~g}$ Bt powder, and $6 \mathrm{~L}$ water; in Section 3, cabbage plants were treated with a mixture of Bt and chlorantraniliprole 2000X-1000X, $3 \mathrm{~g} \mathrm{Bt}$, plus $6 \mathrm{~mL}$ chlorantraniliprole into $6 \mathrm{~L}$ water; and in Section 4 plants were treated with chlorantraniliprole 300X, $20 \mathrm{~mL} 5 \%$ chlorantraniliprole, plus $6 \mathrm{~L}$ water. These four sections were subjected to a second treatment as follows: (1) no treatment applied (FOH-DBM strain); (2) sprayed with Bt 8000X, $1.25 \mathrm{~g} \mathrm{Bt}$ powder GO33A, and $10 \mathrm{~L}$ water (the Bt-DBM strain); (3) treatment 16000X-3200X, $0.625 \mathrm{~g}$ Bt powder, $0.125 \mathrm{~mL} 5 \%$ chlorantraniliprole, and $10 \mathrm{~L}$ water (the BtC-DBM strain); and (4) treated with chlorantraniliprole 1600X, $6.25 \mathrm{~mL} 5 \%$ chlorantraniliprole, plus $10 \mathrm{~L}$ water (the CL-DBM strain) (Figure S1).

\subsection{Insecticides and Chemical Reagents}

The insecticides used were chlorantraniliprole (200 $\left.\mathrm{g} \mathrm{L}^{-1} \mathrm{SC}\right)$, purchased from DuPont Agricultural Chemicals Ltd. (USA) and Bt product (GO33A), which was provided by 
Huazhong Agricultural University. The other chemicals and reagents were the same as described in our previous study [42].

\subsection{Leaf Bioassay}

The chlorantraniliprole, Bt product (GO33A), and the mixture of Bt and chlorantraniliprole $(\mathrm{Bt}+\mathrm{Chl})$ were used to determine the resistance level using leaf-dip bioassays. The resistance level was compared by determining the $\mathrm{LC}_{50}$ values of four DBM strains subjected to selection (see above). Insecticide solutions were prepared as serial dilutions with $100 \mathrm{~mL}$ distilled water containing $0.1 \%$ Triton X-100 (v/v). We used a control and 7 doses of each insecticide, $0.2-15 \mathrm{ppm}$ (low-high) for the Bt product, 3.9-250 ppm for chlorantraniliprole, and 4-257 ppm for Bt $+\mathrm{Chl}(7.5 \mathrm{ppm}$ of $\mathrm{Bt}+125 \mathrm{ppm}$ of chlorantranilip-

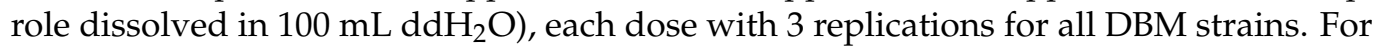
each concentration, three-leaf discs were dipped in each insecticide solution for 12-15 s, followed by air drying at room temperature for $2 \mathrm{~h}$. The control leaf discs were dipped in a distilled water solution containing $0.1 \%$ Triton $X-100$. Treated leaf discs were placed individually into Petri dishes $(8 \mathrm{~cm} \mathrm{D} \times 2 \mathrm{~cm} \mathrm{H})$. For each insecticide and dose treatment, ten 3rd instar larvae were placed on a treated cabbage leaf in a plastic petri dish and kept at $25 \pm 2{ }^{\circ} \mathrm{C}, 65 \pm 5 \% \mathrm{RH}$. Mortality data were assessed after $48 \mathrm{~h}$. Larvae unable to move when touched with a fine-brush were considered to be dead. The control mortality was required to be $<10 \%$ further to determine the medial lethal concentration $\left(\mathrm{LC}_{50}\right)$ values.

\subsection{The Joint Action of Insecticides}

We assessed the effectiveness of combinations of Bt and chlorantraniliprole. We evaluated the joint action toxicity of the Bt and chlorantraniliprole mixtures against the four DBM strains. The constituents tested were (1) Bt $+\mathrm{Chl}$; (2) Bt $+(\mathrm{Bt}+\mathrm{Chl})$; and (3) $\mathrm{Chl}+(\mathrm{Bt}+\mathrm{Chl})$ - prepared based on their $\mathrm{LC}_{50}$ using the leaf-dip bioassay method as discussed above. The joint action of the $\mathrm{Bt}$ and chlorantraniliprole was assessed as described previously $[39,52]$. The poison ratios between the treatments were calculated according to the following:

Theoretical mortality of mixture $\mathrm{M}=$ Mortality of $\mathrm{A} \times \mathrm{A} \%$ in $\mathrm{M}+$ Mortality of $\mathrm{B} \times \mathrm{B} \%$ in $\mathrm{M}$

$$
\text { Poison ratio of a mixture }=\frac{\text { Actual mortality }}{\text { Theoretical mortality }} \times 100
$$

In the equations, $\mathrm{M}$ denotes the mixture of $\mathrm{A}$ and $\mathrm{B}$, and $\mathrm{A}$ and $\mathrm{B}$ are the tested insecticides. A poison ratio $>1.0$ indicates a synergistic effect, a poison ratio $<1.0$ an antagonistic effect, while a poison ratio equal to 1.0 is an additive effect.

\subsection{Enzyme Activity Assay}

To determine the glutathione transferase (GST), carboxyl-esterase (CarE), cytochrome P450 monooxygenases (MFO), and acetyl-cholinesterase (AChE) activity in the four selected strains of DBM, 30 3rd to 4th instar larvae were used for enzyme source preparation. Larvae were placed in a glass homogenizer filled with $1000 \mu \mathrm{L}$ of $0.1 \mathrm{M}$ sodium phosphate buffer ( $\mathrm{pH}$ 7.0). After grinding, the homogenate was centrifuged at $12,000 \times g$ for $5 \mathrm{~min}$ at $4{ }^{\circ} \mathrm{C}$. The resulting homogenate supernatant from each strain was diluted 10 -fold and used as the enzyme source.

The GST enzyme activity was measured using 1-chloro-2,4-dinitrobenzene (CDNB) as a substrate [53]. Briefly, the working solution contained $100 \mu \mathrm{L}$ of enzyme source, $50 \mu \mathrm{L}$ of $1.2 \mathrm{mM}$ CDNB, $50 \mu \mathrm{L}$ of $0.2 \mathrm{M}$ sodium phosphate buffer (pH 7.5), and $100 \mu \mathrm{L}$ of $12 \mathrm{mM}$ GSH. PBS was added in the control instead of the enzyme source. The optical density was recorded by using a Tecan Spark Spectrophotometer at $340 \mathrm{~nm}$ at an interval of $15 \mathrm{~s}$ for 5 min.

The CarE activity test was conducted by the method as reported in previous research [54]. Firstly, $50 \mu \mathrm{L}$ enzyme sources of each strain were added separately into 
micro-plate wells followed $200 \mu \mathrm{L}$ of $0.2 \mathrm{~mol} / \mathrm{L}$ (pH 6.0) sodium phosphate buffer (prepared with $1 \mathrm{mmol} \mathrm{L}^{-1} \alpha$-NA acetate and $0.5 \mathrm{~g} \mathrm{~L}^{-1}$ fast blue salt). Optical density was recorded at $450 \mathrm{~nm}$ with intervals of $12 \mathrm{~s}$ for 30 times at $27^{\circ} \mathrm{C}$.

The AChE enzyme activity was determined by adopting the method as described previously [55], using iodide thiogenic acetylcholine (ATchI) as a substrate. The enzymes incubation was done by using a $50 \mu \mathrm{L}$ enzyme source (50 $\mu \mathrm{L}$ contains $0.1 \%$ Triton-100), $0.1 \mathrm{~mol} / \mathrm{L}$ phosphate buffer (pH 7.5, $100 \mu \mathrm{L}$ ATchI), and $100 \mu \mathrm{L}$ of $0.05 \mathrm{mmol} / \mathrm{L}$ DTNB placed in 96-well plate. The density was recorded at $405 \mathrm{~nm}$ with an interval of $30 \mathrm{~s}$ for $15 \mathrm{~min}$.

For the P450 activity, p-NA was used as the substrate [47]. The total reaction mixture contained $56 \mu \mathrm{L}$ of enzyme source homogenate, and $0.1 \mathrm{~mol} \mathrm{~L}^{-1}$ sodium phosphate solutions (pH 7.5) containing 1mM of DTT, $1 \mathrm{mM}$ of PTU, $1 \mathrm{mM}$ of EDTA, and $1 \mathrm{mM}$ of PMSF. This solution was incubated in a water bath at $34{ }^{\circ} \mathrm{C}$ for $30 \mathrm{~min}$. The absorbance at $405 \mathrm{~nm}$ was recorded using a micro-plate spectra photometer reader.

\subsection{Validation of Gene Expression}

The expression levels of four genes, namely, PxGST, AChE, CarE, and MFO, were investigated in four DBM strains. Total RNA was extracted from 3rd instar larvae of each DBM strain according to the manufacturer's protocol of the EASYspin RNA isolation kit (Biomed, Beijing). Then, M-MLV reverse transcriptase (Takara Bio Inc, Kusatsu, Shiga, Japan) was used for the first-strand cDNA synthesis. The primers were synthesized by Invitrogen Trading (Shanghai) Co., Ltd. The primer details are provided in Table S2. The qRT-PCR (quantitative real-time PCR) was conducted according to the protocol of our previous research [51]. Actin was used as a housekeeping gene. The relative gene expression levels in four DBM strains were calculated using the $2^{-\Delta \Delta C T}$ method.

\subsection{Statistical Analysis}

The $\mathrm{LC}_{50}$ with fiducial limits, chi-square $\left(x^{2-}\right)$ values, and the slope of the concentration -mortality and their standard errors were determined by probit analysis using POLOPC [56]. All mortality (\%) data were corrected using Abbott's formula [57]. The data generated from enzyme analysis was analyzed by Microsoft Office Excel 2013 and shown as MOD min $^{-1} \mu \mathrm{g}$ protein ${ }^{-1}$ for PxGST, CarE, and AChE, and nmol mg protein ${ }^{-1}$ for MFO. Significant differences in the poison ratio, enzyme activities, and gene expression were analyzed by General Linear Model (GLM) followed by an LSD test (Statistix 9.1 version 2004).

Supplementary Materials: The following are available online at https:/ /www.mdpi.com/2072-665 1/13/3/227/s1, Figure S1: Experiment layout and treatments application in the greenhouse; Table S1: Resistance of FOH-DBMs to different insecticides, Table S2: Primer sequences and amplification characteristics of the candidate reference genes for qRT-PCR studies in Plutella xylostella.

Author Contributions: Conceptualization, M.Z.S. and Z.-Y.L.; data curation, F.Y.; methodology, M.Z.S. and L.H.; project administration, Z.-Y.L.; resources, C.S. and J.Z.; writing-original draft, M.Z.S.; writing-review and editing, Z.-Y.L. All authors have read and agreed to the published version of the manuscript.

Funding: This research was funded by the National Key Project of Research and Development Plan (2017YFD0201204 and 2018YFD0201200), Science and Technology Planning Project of Guangdong Province (2019B020217003-05), National Natural Science Foundation of China (Grant No: 31701819) and President Foundation of Guangdong Academy of Agricultural Sciences (Grant No: BZ201911).

Institutional Review Board Statement: Not applicable.

Informed Consent Statement: Not applicable.

Data Availability Statement: The data presented in this study are available in Supplementary Materials. 
Acknowledgments: We are grateful to Myron Philip Zalucki and John Trumble for advice and editing of this paper.

Conflicts of Interest: The authors are not aware of any affiliations, memberships, funding, or financial holdings that might be perceived as affecting the objectivity of this article.

\section{References}

1. Furlong, M.J.; Wright, D.J.; Dosdall, L.M. Diamondback Moth Ecology and Management: Problems, Progress, and Prospects. Annu. Rev. Ėntomol. 2013, 58, 517-541. [CrossRef]

2. Jaleel, W.; Saeed, S.; Naqqash, M.N.; Sial, M.U.; Ali, M.; Zaka, S.M.; Sarwar, Z.M.; Ishtiaq, M.; Qayyum, M.A.; Aine, Q.U.; et al. Effects of temperature on baseline susceptibility and stability of insecticide resistance against Plutella xylostella (Lepidoptera: Plutellidae) in the absence of selection pressure. Saudi J. Biol. Sci. 2020, 27, 1-5. [CrossRef]

3. Jaleel, W.; Saeed, S.; Saeed, Q.; Naqqash, M.N.; Sial, M.U.; Aine, Q.U.; Yanyuan, L.; Rui, Z.; He, Y.; Lu, L. Effects of three different cultivars of cruciferous plants on the age-stage, two-sex life table traits of Plutella xylostella (L.)(Lepidoptera: Plu-tellidae). Entomol. Res. 2019, 49, 151-157. [CrossRef]

4. Zhang, S.; Zhang, X.; Shen, J.; Mao, K.; You, H.; Li, J. Susceptibility of field populations of the diamondback moth, Plutella xylostella, to a selection of insecticides in Central China. Pestic. Biochem. Physiol. 2016, 132, 38-46. [CrossRef] [PubMed]

5. Zalucki, M.P.; Shabbir, A.; Silva, R.; Adamson, D.; Liu, S.S.; Furlong, M.J. Estimating the Economic Cost of One of the World's Major Insect Pests, Plutella xylostella (Lepidoptera: Plutellidae): Just How Long Is a Piece of String? J. Econ. Èntomol. 2012, 105, 1115-1129. [CrossRef] [PubMed]

6. Liu, Y.-Q.; Shi, Z.-H.; Zalucki, M.P.; Liu, S.-S. Conservation biological control and IPM practices in Brassica vegetable crops in China. Biol. Control. 2014, 68, 37-46. [CrossRef]

7. Xia, Y.; Lu, Y.; Shen, J.; Gao, X.; Qiu, H.; Li, J. Resistance monitoring for eight insecticides in Plutella xylostella in central China. Crop. Prot. 2014, 63, 131-137. [CrossRef]

8. Tabashnik, B.; Huang, F.; Ghimire, M.N.; Leonard, B.R.; Siegfried, B.D.; Rangasamy, M.; Yang, Y.; Wu, Y.; Gahan, L.J.; Heckel, D.G.; et al. Efficacy of genetically modified Bt toxins against insects with different genetic mechanisms of resistance. Nat. Biotechnol. 2011, 29, 1128-1131. [CrossRef] [PubMed]

9. Wang, X.; Wu, Y. High Levels of Resistance to Chlorantraniliprole Evolved in Field Populations of Plutella xylostella. J. Econ. Èntomol. 2012, 105, 1019-1023. [CrossRef]

10. Bass, C.; Denholm, I.; Williamson, M.S.; Nauen, R. The global status of insect resistance to neonicotinoid insecticides. Pestic. Biochem. Physiol. 2015, 121, 78-87. [CrossRef]

11. Baxter, S.W.; Chen, M.; Dawson, A.; Zhao, J.-Z.; Vogel, H.; Shelton, A.M.; Heckel, D.G.; Jiggins, C.D. Mis-Spliced Transcripts of Nicotinic Acetylcholine Receptor $\alpha 6$ Are Associated with Field Evolved Spinosad Resistance in Plutella xylostella (L.). PLoS Genet. 2010, 6, e1000802. [CrossRef] [PubMed]

12. Sonoda, S. Molecular analysis of pyrethroid resistance conferred by target insensitivity and increased metabolic detoxification in Plutella xylostella. Pest Manag. Sci. 2010, 66, 572-575. [CrossRef] [PubMed]

13. Bass, C.; Field, L.M. Gene amplification and insecticide resistance. Pest Manag. Sci. 2011, 67, 886-890. [CrossRef] [PubMed]

14. Li, X.; Schuler, M.A.; Berenbaum, M.R. Molecular Mechanisms of Metabolic Resistance to Synthetic and Natural Xenobiotics. Annu. Rev. Èntomol. 2007, 52, 231-253. [CrossRef] [PubMed]

15. Wang, R.; Qu, C.; Wang, Z.; Yang, G.; Luo, C. Cross-resistance, biochemical mechanism and fitness costs of laboratory-selected resistance to pyridalyl in diamondback moth, Plutella xylostella. Pestic. Biochem. Physiol. 2020, 163, 8-13. [CrossRef] [PubMed]

16. Karunaratne, S.; Weerakoon, K. Involvement of metabolic and insensitive acetylcholinesterase mechanisms in insecticide re-sistance of rice insect pests and predatory populations from Batalagoda, Sri Lanka. J. Natn. Sci. 2007, 35, $103-108$.

17. Briefs, I. Global status of commercialized biotech/GM crops in 2017: Biotech crop adoption surges as economic benefits accumulate in 22 years. ISAAA Brief 2017, 53, 25-26.

18. James, C. Global Review of Commercialized Transgenic Crops: 2002 Feature: Bt Maize; ISAAA Ithaca: New York, NY, USA, 2003; Volume 29.

19. Shabbir, M.Z.; Quan, Y.; Wang, Z.; Bravo, A.; Soberón, M.; He, K. Characterization of the Cry1Ah resistance in Asian corn Borer and its cross-resistance to other Bacillus thuringiensis toxins. Sci. Rep. 2018, 8, 1-9. [CrossRef]

20. He, K.; Wang, Z.; Zhou, D.; Wen, L.; Song, Y.; Yao, Z. Evaluation of Transgenic Bt Corn for Resistance to the Asian Corn Borer (Lepidoptera: Pyralidae). J. Econ. Ėntomol. 2003, 96, 935-940. [CrossRef] [PubMed]

21. Wang, Y.; Wang, Y.; Wang, Z.; Bravo, A.; Soberón, M.; He, K. Genetic Basis of Cry1F-Resistance in a Laboratory Selected Asian Corn Borer Strain and Its Cross-Resistance to Other Bacillus thuringiensis Toxins. PLoS ONE 2016, 11, e0161189. [CrossRef]

22. Zhang, T.; He, M.; Gatehouse, A.M.R.; Wang, Z.; Edwards, M.G.; Li, Q.; He, K. Inheritance Patterns, Dominance and CrossResistance of Cry1Ab- and Cry1Ac-Selected Ostrinia furnacalis (Guenée). Toxins 2014, 6, 2694-2707. [CrossRef] [PubMed]

23. Carrière, Y.; Fabrick, J.A.; Tabashnik, B.E. Can Pyramids and Seed Mixtures Delay Resistance to Bt Crops? Trends Biotechnol. 2016, 34, 291-302. [CrossRef] [PubMed]

24. James, C. Global status of commercialized biotech/GM crops. ISAAA Briefs 2006, 35, 96.

25. Kortenkamp, A. Ten Years of Mixing Cocktails: A Review of Combination Effects of Endocrine-Disrupting Chemicals. Environ. Health Perspect. 2007, 115, 98-105. [CrossRef] 
26. Cang, T.; Dai, D.; Yang, G.; Yu, Y.; Lv, L.; Cai, L.; Wang, Q. Combined toxicity of imidacloprid and three insecticides to the earthworm, Eisenia fetida (Annelida, Oligochaeta). Environ. Sci. Pollut. Res. 2017, 24, 8722-8730. [CrossRef] [PubMed]

27. Legrand, E.; Boulangé-Lecomte, C.; Restoux, G.; Trémolet, G.; Duflot, A.; Forget-Leray, J. Individual and mixture acute toxicity of model pesticides chlordecone and pyriproxyfen in the estuarine copepod Eurytemora affinis. Environ. Sci. Pollut. Res. 2016, 24, 5976-5984. [CrossRef]

28. Zhao, F.; Li, Y.; Huang, L.; Gu, Y.; Zhang, H.; Zeng, D.; Tan, H. Individual and combined toxicity of atrazine, butachlor, halosulfuron-methyl and mesotrione on the microalga Selenastrum capricornutum. Ecotoxicol. Environ. Saf. 2018, 148, 969-975. [CrossRef]

29. Stemele, M. Comparative effects of a selective insecticide, Bacillus thuringiensis var. kurstaki and the broad-spectrum insecticide cypermethrin on diamondback moth and its parasitoid Cotesia vestalis (Hymenoptera; Braconidae). Crop. Prot. 2017, 101, 35-42. [CrossRef]

30. Wang, Y.; Quan, Y.; Yang, J.; Shu, C.; Wang, Z.; Zhang, J.; Gatehouse, A.M.R.; Tabashnik, B.E.; He, K. Evolution of Asian Corn Borer Resistance to Bt Toxins Used Singly or in Pairs. Toxins 2019, 11, 461. [CrossRef]

31. Guo, L.; Liang, P.; Zhou, X.; Gao, X. Novel mutations and mutation combinations of ryanodine receptor in a chlorantraniliprole resistant population of Plutella xylostella (L.). Sci. Rep. 2015, 4, 6924. [CrossRef] [PubMed]

32. Sparks, T.C.; Nauen, R. IRAC: Mode of action classification and insecticide resistance management. Pestic. Biochem. Physiol. 2015, 121, 122-128. [CrossRef]

33. Maa, W.C.J.; Liao, S.C. Culture-dependent variation in esterase isozymes and malathion susceptibility of diamondback moth, Plutella xylostella L. Zool. Stud. Taipei 2000, 39, 375-386.

34. Gong, Y.-J.; Wang, Z.-H.; Shi, B.-C.; Kang, Z.-J.; Zhu, L.; Jin, G.-H.; Weig, S.-J. Correlation between Pesticide Resistance and Enzyme Activity in the Diamondback Moth, Plutella xylostella. J. Insect Sci. 2013, 13, 1-13. [CrossRef]

35. Jiang, T.; Wu, S.; Yang, T.; Zhu, C.; Gao, C. Monitoring Field Populations ofPlutella xylostella(Lepidoptera: Plutellidae) for Resistance to Eight Insecticides in China. Fla. Èntomol. 2015, 98, 65-73. [CrossRef]

36. Khaliq, A.; Attique, M.; Sayyed, A. Evidence for resistance to pyrethroids and organophosphates in Plutella xylostella (Lepidoptera: Plutellidae) from Pakistan. Bull. Èntomol. Res. 2007, 97, 191-200. [CrossRef] [PubMed]

37. Hamilton, J.T.; Attia, F.L. Effects of Mixtures of Bacillus thuringiensis and Pesticides on Plutella xylostella and the Parasite Thyraeella collaris. J. Econ. Èntomol. 1977, 70, 146-148. [CrossRef]

38. De Liguoro, M.; Riga, A.; Fariselli, P. Synergistic toxicity of some sulfonamide mixtures on Daphnia magna. Ecotoxicol. Environ. Saf. 2018, 164, 84-91. [CrossRef]

39. Rizvi, S.A.H.; Ling, S.; Tian, F.; Xie, F.; Zeng, X. Toxicity and enzyme inhibition activities of the essential oil and dominant constituents derived from Artemisia absinthium L. against adult Asian citrus psyllid Diaphorina citri Kuwayama (Hemiptera: Psyllidae). Ind. Crop. Prod. 2018, 121, 468-475. [CrossRef]

40. Feyereisen, R. Insect CYP Genes and P450 Enzymes. Insect Mol. Biol. Biochem. 2012, 236-316. [CrossRef]

41. Oakeshott, J.G.; Claudianos, C.; Campbell, P.M.; Newcomb, R.D.; Russell, R.J. Biochemical Genetics and Genomics of Insect Esterases. Ref. Modul. Life Sci. 2019, 5. [CrossRef]

42. Hu, Z.-D.; Feng, X.; Lin, Q.-S.; Chen, H.-Y.; Li, Z.-Y.; Yin, F.; Liang, P.; Gao, X.-W. Biochemical Mechanism of Chlorantraniliprole Resistance in the Diamondback Moth, Plutella xylostella Linnaeus. J. Integr. Agric. 2014, 13, 2452-2459. [CrossRef]

43. Nehare, S.; Moharil, M.; Ghodki, B.; Lande, G.; Bisane, K.; Thakare, A.; Barkhade, U. Biochemical analysis and synergistic suppression of indoxacarb resistance in Plutella xylostella L. J. Asia-Pac. Èntomol. 2010, 13, 91-95. [CrossRef]

44. Chen, X.; Zhang, Y.-L. Identification and characterisation of multiple glutathioneS-transferase genes from the diamondback moth, Plutella xylostella. Pest Manag. Sci. 2014, 71, 592-600. [CrossRef]

45. Wang, N.; Qiu, X.; Ren, X.; Niu, F.; Wang, K. Resistance selection and biochemical characterization of spinosad resistance in Helicoverpa armigera (Hübner) (Lepidoptera: Noctuidae). Pestic. Biochem. Physiol. 2009, 95, 90-94. [CrossRef]

46. Yalçın, M.; Mermer, S.; Kozacı, L.D.; Turgut, C. Insecticide resistance in two populations of Tuta absoluta (Meyrick, 1917) (Lepidoptera: Gelechiidae) from Turkey. Turk. J. Èntomol. 2015, 39, 137-145. [CrossRef]

47. Qian, L.; Cao, G.; Song, J.; Yin, Q.; Han, Z. Biochemical mechanisms conferring cross-resistance between tebufenozide and abamectin in Plutella xylostella. Pestic. Biochem. Physiol. 2008, 91, 175-179. [CrossRef]

48. Yu, X.-Q.; Kanost, M.R. Manduca sexta lipopolysaccharide-specific immulectin-2 protects larvae from bacterial infection. Dev. Comp. Immunol. 2003, 27, 189-196. [CrossRef]

49. Pavlidi, N.; Vontas, J.; Van Leeuwen, T. The role of glutathione S-transferases (GSTs) in insecticide resistance in crop pests and disease vectors. Curr. Opin. Insect Sci. 2018, 27, 97-102. [CrossRef] [PubMed]

50. Xu, L.-N.; Wang, Y.-Q.; Wang, Z.-Y.; Ying-Hui, L.; Ling, Y.-H.; Zhen-Ying, W. Transcriptome differences between Cry1Ab resistant and susceptible strains of Asian corn borer. BMC Genom. 2015, 16, 1-15. [CrossRef]

51. Shabbir, M.Z.; Zhang, T.; Prabu, S.; Wang, Y.; Wang, Z.; Bravo, A.; Soberón, M.; He, K. Identification of Cry1Ah-binding proteins through pull down and gene expression analysis in Cry1Ah-resistant and susceptible strains of Ostrinia furnacalis. Pestic. Biochem. Physiol. 2020, 163, 200-208. [CrossRef]

52. Ma, T.; Yan, H.; Shi, X.; Liu, B.; Ma, Z.; Zhang, X. Comprehensive evaluation of effective constituents in total alkaloids from Sophora alopecuroides L. and their joint action against aphids by laboratory toxicity and field efficacy. Ind. Crop. Prod. 2018, 111, 149-157. [CrossRef] 
53. Han, Y.; Yu, W.; Zhang, W.; Yang, Y.; Walsh, T.; Oakeshott, J.G.; Wu, Y. Variation in P450-mediated fenvalerate resistance levels is not correlated with CYP337B3 genotype in Chinese populations of Helicoverpa armigera. Pestic. Biochem. Physiol. 2015, 121, 129-135. [CrossRef] [PubMed]

54. Han, Z.; Moores, G.D.; Denholm, I.; Devonshire, A.L. Association between Biochemical Markers and Insecticide Resistance in the Cotton Aphid, Aphis gossypiiGlover. Pestic. Biochem. Physiol. 1998, 62, 164-171. [CrossRef]

55. Ellman, G.L.; Courtney, K.; Andres, V.; Featherstone, R.M. A new and rapid colorimetric determination of acetylcholinesterase activity. Biochem. Pharmacol. 1961, 7, 88-95. [CrossRef]

56. LeOra, S. Poloplus, a User's Guide to Probit or Logit Analysis; LeOra Software: Berkeley, CA, USA, 2003.

57. Abbott, W.S. A Method of Computing the Effectiveness of an Insecticide. J. Econ. Èntomol. 1925, 18, 265-267. [CrossRef] 